\title{
关于信息技术给力农村小学数学教学的思考
}

\author{
蒙智惠
}

重庆市沙坪坝区阳光家园小学

DOI:10.32629/jief.v2i5.1451

[摘要] 农村中小学教育是国家非常重视的问题之一，政府投入大量的人力、物力对农村中小学校的校舍、信息化设施设备进行了全面改善, 但是学校的硬件配置与使用情况还是值得我们思考与探索。

[关键词] 信息技术; 小学数学; 运用策略

中图分类号: G633.67 文献标识码: A

数学是一门集抽象性与逻辑性于一体的学科, 学生在面对这样的学 科之时, 难免产生无力之感。随着现代信息技术的不断发展, 其以形象 直观、声形兼备、形式多样的优势迅速 “占领” 小学数学 “阵地” , 并 深受广大小学数学教育工作者的青睐, 其极大地增强了数学教学的直观 性和趣味性, 丰富了教学内容, 还有效突破教学重难点知识, 加强学生 的认知, 从而有效的提升了课堂教学效率。然而, 从我所在的农村学校 到周边的各中小学调查了解得知, 诸多农村学校对多媒体的使用情况堪 忧。那么, 在小学数学教学中如何更好地使用信息技术便成为广大教师 值得探究的问题, 本文结合我所在学校及周边学校的情况, 拟从信息技 术在小学数学教学中的 “作用”、“现状”、“运用策略” 几方面来谈 谈自己的观察和思考。

\section{1 信息技术给力小学数学教学的作用}

1.1 信息技术给力数学教学, 让生活情景走进课堂, 激发学生的学 习兴趣

《义务教育数学课程标准》指出, 数学源于生活, 并为生活服务。我 们可以利用信息技术的丰富性、及时性, 将各种生活信息引入数学课堂, 使学习内容更加丰富多彩, 在贴近学生的生活实际同时, 还能够让学习 内容极具时代气息。我在教学之时, 便借助信息技术将生活情境有效地 引入数学课堂, 创设自主学习的平台, 借以激发学生自主学习的意识和 兴趣, 调动学生学习积极性, 促使学生主动参与到数学学习活动当中, 在提高学生学习能力的同时, 还能够逐步丰富学生的情感体验, 提高学 生的学习水平。

例如, 在教学可能性时, 我将生活中学生在小卖部参加商家有奖活 动和红十字举办的中国福利彩票会的现场情景呈现出来, 让学生讨论: （1）商家举办的有奖活动中奖的可能性大吗? 这种活动公平吗?为什么? ( 2 ) 为什么那么多的同学愿意参与? 商家的目的是什么? 你还愿意参加 这样的活动吗? (3) 中国福利彩票中奖的可能性大吗? 为什么那么多的 大人参与其中? （4）你知道中国红十字会是干什么的吗? 你愿意去买这 个福利彩票吗? 通过信息技术将这两个画面呈现出来学生讨论, 不仅让 学生懂得了可能性的大小, 明白了商家销售骗钱的策略, 而且让学生了 解红十字会存在的意义, 明白有多数的中国人会在别人危难之际向人伸 出援助之手, 令学生明白予人玫瑰, 手有余香的道理, 从而鼓励学生今 后可以成为他们其中的一员。通过这样的教学, 渗透了生活的实际问题, 学生自然会产生学习兴趣, 探索求知的欲望便油然而生, 更是成功地实 现了让学生由 “要我学” 向 “我要学” 的心态转变。
1.2 信息技术给力数学教学, 让数学素材丰富多彩, 学生乐学好学

数学教材中存在诸多抽象的数学知识, 如推导公式定理等, 学生在 理解之时难免会产生手足无措之感, 若在教学之中巧妙地借助多媒体演 示整个推导过程, 不仅可以有效帮助教师突破教学重难点, 还可以利用 生动形象的方式, 助力学生理解相关知识, 从而提升学生的学习效率。 例如, 我在教学长方形的周长时, 为了帮助学生理解周长的定义, “围绕 物体一周的长度叫周长”, 我用 flash 演示绕物体一周的曲线, 由于用的 是课件演示, 画面生动, 又伴随声音, 学生注意力集中, 印象深刻。接 着, 我又让学生拿出准备好的物体, 动手摸一摸物体的周长, 通过手脑 结合, 了解知识的形成过程, 符合小学生的认识过程, 课堂气氛活跃, 学生觉得学习数学是一件快乐的事情。

1.3 信息技术给力数学教学, 让教学方法更加多样, 提高课堂教学 效果

《课程标准与教学大纲对比研究》指出, 动手实践, 自主探索与合作 交流是学生学习的重要方式。信息技术给力数学教学, 可以在教学中把 信息技术、信息资源、信息方法和教学内容, 教学过程结合起来, 有机 统一在同一个时空平台上, 借以更好地完成教学任务。信息技术给力小 学数学, 是教与学方式的转变。例如, 我在教学教学《时 分 秒》时, 一般的方法就是老师带着实物钟, 在课堂上演示, 因为拿着时钟操作, 有时候老师的手挡住了学生的视线, 学生观察就有一点难度, 有了信息 技术的帮助, 可以把时钟搬上荧屏, 让学生反复观看时针, 分针, 秒针 的运行情况。聆听秒针的滴答声, 了解一秒, 十秒的时间长度, 感受时 间。

1.4 信息技术给力数学教学, 让数学知识容量加大, 强化学习的效 果

在教学中, 黑板能够呈现的内容有限, 因此, 老师往往能有效的完 成新课教学的步骤, 而在练习和巩固环节, 往往受限, 有了信息技术, 老师可以先做好课件, 在课堂上显示, 这样学生就可以做大量的口头练 习了, 或者教师将练习题目输入电脑, 学生就可以在电脑上练习了, 节 省了时间, 又加大了练习的容量, 通过大量的练习, 能及时反馈学生的 学习效果, 达到巩固复习的目的。心理学研究表明, 学生对一问题反馈 越及时, 记忆就越深刻, 学习的效果就越好。

对农村学校来说, 信息技术的使用现状令人堪忧。那么, 接下来我 会就我所在学校谈谈信息技术使用的现状。

2 农村学校信息技术给力数学教学的现状 


\section{1 信息技术培训效果差强人意}

几乎每个学校都有自己的管理培训机制, 但是培训老师一般来自本 校, 知识水平有限, 很多学校计算机的专业老师少, 一般都是半路出家 的老师在担当计算机教学, 本身专业素养不高, 加上电脑数量少, 很多 老师缺乏练习, 导致校本计算机培训落实不到实处。另外, 有部分能够 很好使用信息技术的老师，却缺乏一种 “分享” 意识，不愿分享自己的 技术或劳动成果, 导致优秀技术和经验只掌握在少数人手里, 那么提升 整个教师信息素养的工作便深陷泥潭之中, 而无法自拔。一般来说, 信 息素养包含有技术和人文两个层面的意义: 在技术层面上, 信息素养反 映的是人们搜索、鉴别、篮选、利用信息的能力, 以及有效地在教学过 程中使用信息技术的技能; 从人文层面上看, 则反映人们对信息的情感、 态度和价值观, 它建立在技术层面的基础上, 涉及到独立学习, 协同工 作, 个人和社会责任等各方面的内容。因为文化层次, 年龄结构不一, 不少教师信息素养意识不强, 课堂改革热情不高, 影响了教师使用多媒 体的积极性。使用的频率也不高, 一般在公开课, 示范课上用用。平时 教学几乎仍然采用传统教学, 而计算机很多功能都未开发利用。

2.2 部分教师运用信息技术存在误区

\section{2.1 过分信赖信息技术}

有些教师认为一堂课没有网络, 没有多媒体课件, 那肯定不是一堂 好课, 有些老师甚至完全依赖信息技术, 而脱离课本, 出现本末倒置的 情况。如, 在校本教研一节数学课上, 内容为对称图形, 主要教学目标 要求学生认识和设计对称图形, 任课教师首先展示各色各样各式的对称 图案, 看得学生目瞪口呆, 赞不绝口, 而忘记了老师提出的问题。而且 老师没能把课件和课本联系, 课本上有展示简单的对称图形的折叠及裁 剪, 老师却忘了示范。她忙得不可开交地展示课件时, 学生却清闲的无 聊。这样的教学脱离了理论和实践, 也未培养学生实际操作能力, 更别 谈创新能力了。

\section{2 .2 教学中存在无目的运用信息技术情况}

信息资源，技术手段的运用和处理不当，导致无目的地使用信息技 术课件, 冲淡了教学内容及目标, 不利于学生对重难点的把握。信息技 术教学, 它具有展示教学内容形象易懂的优点, 长期大量使用, 会使学 生知其表而不知其里, 只会产生好奇, 而忽视教学内容。

\subsection{3 教学中信息技术选用单一化}

在信息技术展示教学内容中, 老师们对于教学媒体的选择就非常单 一, “有了多媒体, 都争先恐后的选用多媒体教学, 都用演示型计算机 这一媒体, 而把录音机、小黑板、挂图、模型等直观的常规性的教学手 段弃之一旁”。舍轻就重, 顾此失彼。即便使用计算机演示也是单向演 示居多, 显得结构单一, 而且教师不示范, 不板书, 从而淡化了教师指 导作用。课件的作用仅仅是提起了学生课堂上好奇的兴趣, 可是真正面 对文本, 学生反而失去了兴趣。有些课, 文本还没有弄清楚, 就让学生 离开书本去传授从网络上得到的一些似懂非懂、深奥的数学知识, 美其 名曰开拓延伸。所以, 课件使用没有做到适时适度有效。

针对以上问题和不足, 我们应该找到什么样的策略呢?

\section{3 农村中小学信息技术给力数学教学的策略}

3.1 领导提高认识, 加大师资培训力度, 创建浓厚的信息技术教学 氛围

作为领导, 要督促教师积极参与培训业务, 多学习理论知识, 更要
在每期教研教改中规定教师使用多媒体教学, 踏踏实实做课件, 将多媒 体教学落到实处, 还要要经常带着老师 “走出去” 参观学习, 也要 “引 进来” 专业信息技术老师, 传授相关经验, 以便学校教师能够借鉴其先 进理论经验, 并通过实际操作的具体程序, 使全校形成 “全员参与, 全 程参与” 的良好培训局面。教育和引导教师要有 “危机意识、忧患意识、 创新意识”，树立终身学习理念，不断学习提高现代教育技术。

3.2 深化对教师信息素养的认识, 提高教师的教育教学水平

教育部《关于推进教师教育信息化建设的意见》中明确指出 “要实 现信息技术在中小学逐步普及和应用, 建设一支数量足够、质量合格的 具有较高信息素养的中小学师资队伍是关键。” 教师信息素养的价值, 不 仅体现在将信息技术有效运用于教学和管理, 而是反映了全面实现教育 目标的基本要求。很难想象, 一个缺乏信息素养的教师能够培养出良好 信息素养的学生, 更谈不上如何正确引导学生上网了。目前, 鉴于学生 游戏成瘾的现状, 一些教师不敢鼓励学生利用网络进行学习, 视网络为 洪水猛兽的观念也隐含着教师自身信息素养与教育技术能力的缺失, 从 而也不可能使网络成为教师辅助教学、专业发展的有效手段。

教师应该树立终身学习的观念, 不断加强自己的业务学习, 积极学 习网络的知识, 加强网络认识, 积极引导学生利用网络提高学习成绩。

3.3 课件制作要关注学科特点, 关注学生特点, 注重实效

信息技术教学只是一种辅助教学, 防止利用信息技术优势包办代替 教师作用, 避免过分依赖信息技术, 忽视学生人文素质培养而影响教学 的实际功效和长远目标的实现。课件要体现学科特点和教学规律。数学 注重引导思维发展, 盯准一个 “理” 字, 所以课件不仅仅为追求动态效 果, 直观性, 演示性, 而要符合学科规律, 因科因课制宜, 扬长避短, 优势互补, 忌求大求全, 既要发挥计算机优势, 又要发挥教师主导作用, 根据教学内容、对象和各种配套设施的具体情况决定合理使用信息技术 辅助教学。

学生是认识和发展的主体, 是具有独立地位和极大认知潜能的实践 者, 学生自主探究解决问题的能力, 教师无法代劳, 教师必须走下课堂, 与生为善, 以退求进, 以学论教, 以学定教, 启发学生能动性, 引导他 们自己尽可能地合作式探究问题, 并独立解决问题等能力。因此, 信息 技术的使用要更多地体现学生的主体地位。教师要做到 “三思合一” (教 师思路, 学生思路, 教材思路), 才能更好发挥学生主体作用, 提高教学 效果, 获得教学成功。

总之, 信息技术不仅带来教育形式和学习方式的重要变化, 更重要 的是对教育思想、观念、模式、内容、方式产生深刻影响。开拓了全新 的教学理念, 将教学推进到一个新领域。但是信息技术在教学中的作用 是有条件的, 不可能解决教学中的所有问题, 不可将其视为万能。我们 要在教学过程中使其 “优势互补”, 优化课堂教学, 提高教学效率, 以 此实现教育的目的任务。

\section{[参考文献]}

$[1]$ 施龙福.农村小学数学线上教学现状与对策 [J]. 试题与研 究,2020(24):51-52.

[2]刘艳芳.浅谈如何打造农村小学数学兴趣课堂[J]. 现代农村科 技,2020(08):98.

[3]赵智强.农村小学数学阶梯教学法的研究[J].科学咨询(科技 - 管 理),2020(08):260. 